\title{
Bioinformatics evaluation of the homologues of Schistosoma mansoni biomarker proteins of bladder cancer in other Schistosoma species
}

\author{
Folayowon JO', Adebayo AS², Isokpehi RD³, Anumudu CI*1 \\ ${ }^{1}$ Department of Zoology, University of Ibadan, Ibadan Nigeria, \\ ${ }^{3}$ Bethune -Cookman University Daytona Beach, Florida, USA \\ *Corresponding author \\ Email cianumudu@yahoo.com
}

\begin{abstract}
Schistosomiasis remains a public health problem in developing countries. An ideal diagnostic test capable of detecting parasites as early as possible after the onset of infection is therefore highly desired. The identification of biomarker proteins associated with active infection and immune response may constitute the basis for the development of a successful diagnostic test. The aim of this study is to contribute to the development of protein biomarkers for schistosomiasis using a bioinformatics approach. The homologues of 36 previously identified urine biomarker proteins from a Schistosoma mansoni database, were identified in other Schistosoma species using SMARTBLAST and analyzed for similarities and differences using multiple sequence alignment. Of the $36 S$. mansoni biomarker proteins, 29 had homologues with both $S$. haematobium and $S$. japonicum or either of $S$. haematobium and S. japonicum. Most of the 29 S. mansoni biomarker proteins aligned with their homologues with many conserved regions. However, some vital biomarker proteins like venom allergen-like proteins, which had been proposed as a putative drug and vaccine target, showed more semi conserved regions in which the amino acids had similar shape but weakly similar properties. The predictions of 12 markers found in all three species also show that treatment of infections may possibly benefit from the investigational drug Artenimol and specific nutraceuticals or supplements. Experimental evaluation is needed to confirm the potential of the proteins as biomarkers for early diagnosis of schistosomiasis and associated bladder cancer.
\end{abstract}

Keywords: Schistosomiasis; Protein Biomarker; Homologues; bioinformatics 
bioRxiv preprint doi: https://doi.org/10.1101/2020.09.07.285767; this version posted September 7, 2020. The copyright holder for this preprint (which was not certified by peer review) is the author/funder, who has granted bioRxiv a license to display the preprint in perpetuity. It is made available under aCC-BY 4.0 International license.

\section{INTRODUCTION}

Schistosomiasis, also known as bilharzia, is a disease caused by blood-dwelling trematodes belonging to the genus Schistosoma. The genus Schistosoma contains six species that are of major pathological importance to man, Schistosoma haematobium, S. mansoni, S. japonicum, S. mekongi, S. intercalatum, and S. guineensis (French et al., 2018). Of these species of flatworms, S. haematobium S. japonicum and S.mansoni are the main schistosome parasites of man (Masamba et al., 2016). Schistosomiasis remains one of the most prevalent neglected tropical diseases especially in Nigeria, which supposedly has the greatest number of infected people worldwide (Dawaki et al., 2016). Despite the gains in the health care delivery of the past decades, schistosomiasis has prevailed as a health challenge in the tropic and the subtropics. Schistosomiasis is a chronic parasitic infection responsible for nearly 280,000 deaths per year with 200 million people worldwide being infected (Cai et al., 2017). According to the World Health Organization (WHO, 2015), schistosomiasis is second to malaria alone amid the vectorborne diseases in terms of public health and remuneration importance in the tropics. An early diagnostic test would enable more rapid treatment and would interrupt the transmission cycle of the parasite and the progress of the disease (Kardoush et al., 2016). However, the current diagnostic standards for schistosomiasis all depend on the detection of eggs. In addition, as the disease is asymptomatic in its early stages, clinical examinations cannot confirm infection (Weifang et al., 2018).

Human bladder cancer is the fifth to the seventh most common cancer in Western countries. In many tropical and subtropical areas, however, it is the first among all types of cancer, mainly due to the endemic parasitism (Gulia et al., 2017). The urinary form of schistosomiasis, known as urogenital or urinary schistosomiasis is caused by S. haematobium and is widespread in Africa and the Middle East (WHO, 2015). Epidemiological evidence indicates that $S$. haematobium is associated to squamous cell carcinoma of the bladder. In spite of various control measures and eradication methods that have been in use, schistosomiasis still prevails as one of the most debilitating parasitic diseases, typically affecting the poor and the less privileged predominantly in sub-Saharan Africa (Masamba et al., 2016). Efforts to control and eradicate schistosomiasis rely on praziquantel, the only drug available for treatment. However, treatment with praziquantel may sometimes fail, and this may be due to possible drug resistance. There were also case reports of travelers who were infected during their stay in endemic areas and were treated with praziquantel, but resulted in treatment failure (Secor and Montogomery, 2015). Vaccine 
bioRxiv preprint doi: https://doi.org/10.1101/2020.09.07.285767; this version posted September 7, 2020. The copyright holder for this preprint (which was not certified by peer review) is the author/funder, who has granted bioRxiv a license to display the preprint in perpetuity. It is made available under aCC-BY 4.0 International license.

development against this disease has experienced more failure than successes, (although there is currently a vaccine trial going on for schistosomiasis in Africa (Molehin, 2020); therefore, the identification of molecular targets that can induce protective immunity is highly desirable.

The use of biomarkers in basic and clinical research as well as in clinical practice has become so commonplace that their presence as primary endpoints in clinical trials is now accepted almost without question. The identification of biomarker proteins associated with active infection and protective immune response may constitute the basis for the development of a successful vaccine and could also indicate new diagnostic method (Schmitz-Drager et al., 2015). Over the last decade, the number of omics resources used to study this neglected disease has increased considerably, mainly due to advances associated with the development of detection/analysis techniques and mass spectrometry equipment (Hwang et al., 2018).

Identification of biomarker proteins is important in early diagnosis of both schistosomiasis and schistosomiasis associated bladder cancer and has been evaluated in recent studies (Onile et al., 2017); it may also have application in drug and vaccine development for the treatment of the disease. These biomarker proteins were found using S. mansoni database, which is the best curated schistosome species. It is therefore important to know if homologues of these biomarker proteins could be found in other schistosome species, especially in S. haematobium and $S$. japonicum. In this present study, we searched for homologues of the thirty-six Schistosoma mansoni biomarker proteins found in recent studies in S. haematobium and S. japonicum. This could be used for early diagnosis of schistosomiasis and schistosomiasis associated bladder cancer. We also attempted to identify proteins common to all Schistosoma species which could provide targets for developing drugs or vaccines that can be simultaneously effective against all species of the parasite.

Molecular techniques to detect schistosome infections have been developed to facilitate early diagnosis, but these are expensive and suffer from sampling limitations (Yumin et al., 2018; Weerakoon et al., 2018). Serologic assays to detect antibodies against schistosome antigens, however, have proven useful in the clinical diagnosis of schistosomiasis. Zheng et al., (2012) strongly suggest that SjSP-216, a highly expressed gene in the young worm stage, could serve as a potential biomarker for the early immunodiagnosis of $S$. japonicum infections in vertebrate hosts 
The aim of the study is to contribute to the development of protein biomarkers for schistosomiasis diagnosis using a bioinformatics approach. This will be achieved by identifying the homologues of the 36 biomarker proteins from Schistosoma mansoni evaluated in recent study (Onile et al., 2017) in other Schistosoma species using bioinformatics tools. These biomarker protein sequences from S. mansoni will be compared with those from other Schistosoma species to visualize similarities and differences.

\section{RESULTS}

A total of $36 S$. mansoni biomarker proteins (Table 3.1) were used as query for the homology analysis with $S$. haematobium and $S$. japonicum. Out of these, identical proteins were retrieved for twenty-nine proteins (Table 4.1).

\section{Homology Determination}

Of the 36 S. mansoni biomarker proteins (Table 2), 29 had identical proteins with both Schistosoma haematobium and S. japonicum or either of $S$. haematobium and S. japonicum. The biomarker proteins showed varying identities with $S$. haematobium and S. japonicum whole genome shotgun sequence while some of these proteins showed no significant similarity with either S. haematobium or S. japonicum whole genome shotgun sequence.

\section{Multiple Sequence Alignment}

There were conserved regions in the Calreticulin autoantigen homolog (C4Q5I7) of S. mansoni, S. haematobium and of $S$. japonicum (AAC00515.1) showing that the amino acids in the protein sequences have strongly similar properties. The colors in the alignments show the locations of similarity and difference among the sequence based on the chemical nature of the amino acid residues (Figure 1).

Putative actin-1 of S. mansoni (G4VLW2) and the homologue Actin 5C (CAX75500.1) of $S$. japonicum shows conserved regions as well as regions of complete identical nucleotide sequence (Figure 2). Phosphoglycerate hydratase (enolase) showed conserved regions as well as regions of complete identical nucleotide sequence in most of the positions in the alignment (Figure 3) 
Most of the $29 S$. mansoni biomarker proteins aligned with their homologues, giving rise to a shared identical conserved region. However, some vital biomarker proteins like venom allergenlike proteins which had been proposed as putative drug and vaccine target (Huang et al., 2017), showed more of semi conserved regions in which the amino acids had similar shape, but had weakly similar properties (Figure 4).

\section{Potential Therapeutic targets}

For homologues identified consistently in all three species, 10 had potential targets known or being investigated in humans (Table 3). Such compounds included modified nucleotides, phosphatidylcholines, artenimol, and supplemental elements, among others.

Table 1: The 36 identified Schistosoma mansoni biomarker proteins retrieved from Onile $\boldsymbol{e t}$ al., 2017 and their predicted function.

\begin{tabular}{ll}
\hline Protein ID & Schistosoma Protein \\
C4Q4S5 & Tubulin alpha chain \\
C4Q5I7 & Calreticulin autoantigen homolog \\
C4QBN1 & Histone H4 \\
G4LWI2 & Heat shock protein HSP60 \\
G4LYN4 & ADP-ribosylation factor, ARF \\
G4M1M0 & DNA polymerase \\
G4V6R4 & Putative Rab9 \\
G4V8L4 & Putative heat shock protein 70 \\
G4V910 & Putative heat shock protein 70 (HSP70) \\
G4V8L4 & Putative heat shock protein 70 \\
G4VAC9 & Putative uncharacterized protein \\
G4VAD2 & Elongation factor 1- alpha \\
G4VAW0 & Serine/threonine kinase \\
G4VB75 & Cytoplasmic dynein light chain \\
G4VB79 & Voltage-gated potassium channel, KCNQ \\
G4VDD2 & Eukaryotic translation initiation factor 5A \\
G4VG19 & Phosphoglycerate kinase \\
G4VG20 & Phosphoglycerate kinase \\
G4VGA0 & Sodium/potassium-transporting \\
G4VH98 & subunit alpha \\
G4VHN3 & Putative fimbrin/plastin \\
G4VIM7 & ATP synthase subunit beta \\
& cAMP-response element binding protein \\
G4VKT8 & related \\
G4VLJ0 & Putative ATP synthase alpha subunit vacuolar \\
G4VLJ8 & ATP synthase subunit alpha \\
& Fidgetin like-1 \\
\hline
\end{tabular}

\section{Predicted Function}

Structural/ GTPase activity

Binding

Binding

Heat shock protein

Transporter

Binding and catalytic

Binding

Binding/Heat shock protein

Binding/ Heat shock protein

Binding/ Heat shock protein

Unknown

Binding/GTPase activity

Binding

Structural/Motor

Transmembrane transporter

Binding

Kinase

Kinase

Phosphoglycerate kinase

Transporter

Binding

Transporter/binding

Binding

Transporter/ Binding

Transporter/Binding

Binding and catalytic 
G4VLN5

G4VLW1

G4VLW2

G4VM26

G4VMG4

G4VMT3

G4VP51

G4VPE8

G4VPU8

G4VQ01

G4VQ58

\begin{tabular}{ll}
\hline Putative uncharacterized protein & Binding \\
Putative actin & Binding \\
Putative actin-1 & Binding \\
Putative Zinc finger protein & Binding \\
Venom allergen-like (VAL) 3 protein & Unknown \\
Adapter-related protein complex 3, beta subunit & Transporter
\end{tabular}

Putative ADP, ATP carrier protein

Structural/Transporter

Binding

Putative cytoplasmic dynein intermediate Structural/Motor

chain 2

Uncharacterized protein

Unknown

Phosphopyruvate hydratase

Binding

Table 2: Schistosoma mansoni proteins and their retrieved identical proteins

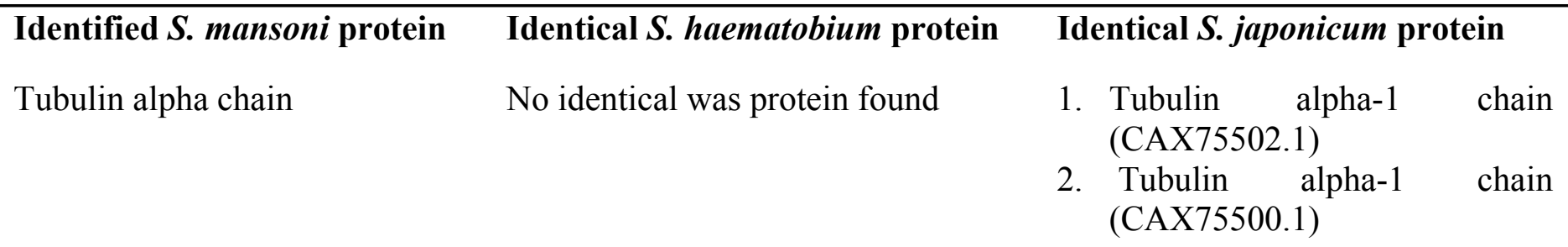

Calreticulin

autoantigen Calreticulin (XP_012799776.1)

Calreticulin (AAC00515.1)

homolog

Heat shock protein HSP60

$60 \mathrm{kDA}$ heat shock protein

mitochondrial (XP_012800213.1)

DNA polymerase

DNA polymerase zeta catalytic No identical protein was found subunit, partial. (XP_012798609.1)

Putative rab9

Ras-related

(XP_012796991.1)

Putative heat shock 70 (Hsp 70)

71 kDA glucose-regulated protein partial (XP_012801946.1)

Putative uncharacterized protein

Elongation factor 1-alpha

Elongation factor 1-alpha
$($ XP_012799780.1)

Actin 5C (CAX72714.1)

1. Eukaryotic translation elongation factor 1-alpha 2 (CAX72182.1) 
Phosphopyruvate hydratase Enolase (XP_01293992.1)

2. Eukaryotic translation elongation factor 1-alpha (CAX79121.1)

(G4VQ58)

Cytoplasmic dynein light chain

Dynein light chain 2, cytoplasmic

No identical protein was found partial (XP_012797326.1)

Eukaryotic translation initiation Eukaryotic translation initiation factor 5A-1 (XP_012791801.1)

SJCHGC00471 (AAW24521.1) factor $5 \mathrm{~A}$

Eukaryotic translation initiation factor 5A (CAX71949.1)

Phosphoglycerate kinase

Phosphoglycerate (XP_012797420.1)

Phosphoglycerate kinase

ATP synthase subunit beta

Camp response element binding protein related
Phosphoglycerate kinase (CAX77838.1)

No identical was protein found kinase Phosphoglycerate (CAX77845.1)

Phosphoglycerate (AAP74224.1)

1. ATP synthase F1 complex beta (AFN58251.1)

2. ATP synthase, $\mathrm{H}+$ transporting mitochondrial F1 complex beta (CAX75390.1) kinase

kinase
Putative ATP synthase alpha V proton ATPase catalytic subunit subunit vacuolar

Fidgetin like-1
1. Hypothetical protein MS3_04489 (XP_012795970.1)

2. Hypothetical protein in MS3_10121 (XP_012801367.1)
A (XP_012793973.1)

Fidgetin-like 1(XP_012798816.1)
SJCHGCO9310

(AAW25271.1)

protein

protein

SJCHGC06318

(AAW25537.1)

protein

Putative uncharacterized protein

Actin 5C (CAX69775.1)

Putative actin

Actin 5C (CAX69775.1)

Zinc finger protein 271 (XP_012799906)

Putative actin-1

Putative zinc finger protein

Venom allergen-like (VAL) 3 Peptidase inhibitor 16, partial Peptidase inhibitor 16 precursor 
protein

(XP_012796982.1)

(CAX78430.1)

Adapter-related protein AP-3 complex subunit beta-2 No identical protein was found complex 3, beta subunit (XP_012793674.1)

Putative ADP, ATP carrier ADP, ATP carrier protein ADP, ATP antiporter protein protein

Putative

inorganic Inorganic (XP_012798695.1)

pyrophosphatase

(4QLZ-A) chain A inorganic pyrophosphatase pyrophosphatase

Putative cytoplasmic dynein Cytoplasmic dynein 1 intermediate No identical protein was found intermediate chain 2 chain 2 (XP 012801212.1)

\section{$\underline{\text { Accession prefix }}$}

AA: reference protein sequence which undergoes continuing curation.

AAC and AAP: GenBank Protein ID for patent proteins.

CAX: EMBL (European Molecular Biology Laboratory) Protein ID.

AP_: Annotated proteins on complete genomic molecule, usually alternate assembly.

XP_: Computed proteins with predicted model 

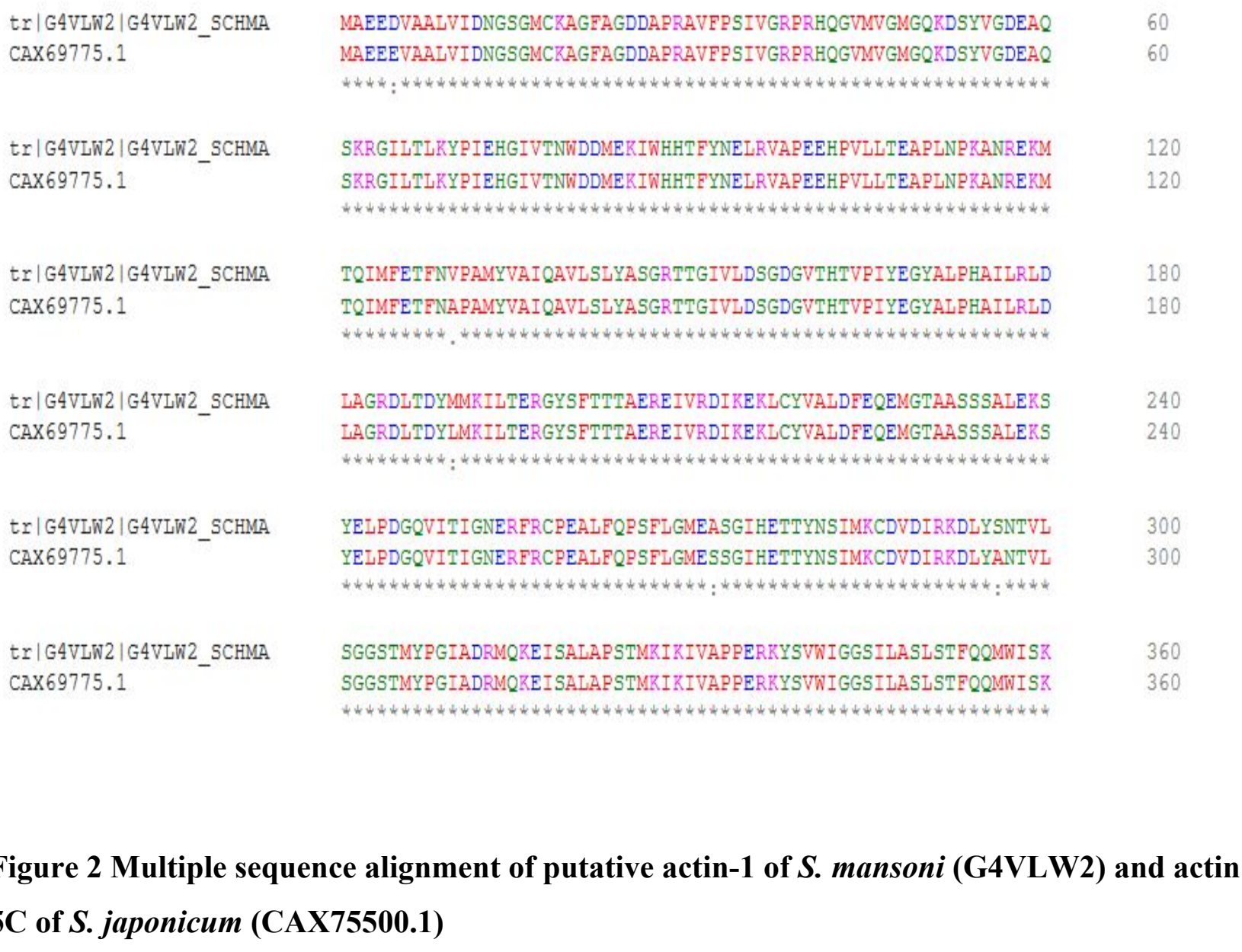

Figure 2 Multiple sequence alignment of putative actin-1 of $S$. mansoni (G4VLW2) and actin 5C of S. japonicum (CAX75500.1)

\section{Legend}

“*” means that the amino acid in that column are identical in all sequence in the alignment. ":" denotes conserved regions i.e. amino acid with strongly similar properties. "." denotes semiconserved regions. The red color shows hydrophobic residues, blue color shows acidic residues, magenta shows basic residues, green shows hydroxyl residues while grey color show unusual amino acids. The colors in the alignments show the locations of similarity and difference among the sequence based on the chemical nature of the amino acid residues 


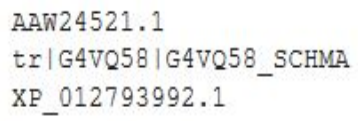

MAI IAIHARQI FDSRGNPTVEVDLRTAKGLFRAAVPSGASTGVHEALELRDTNSKAYMCK MSILTIHARQI FDSRGNPTVEVDLRTSKGLFRAAVVSGASTGVHEAIELRDINSKAYMKK MSIISIHARQIFDSRGNPTVEVDLRTSKGLFRAAVPSGASTGVHEALELRDTKSKAYMGK

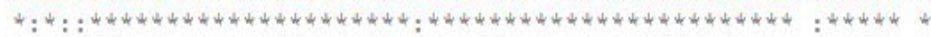

GVLTAVSNVNNI IAPALLKKQI PVTNQSEVDQFMIELDGKENKGNLGANAILGVSLAVCK GVLTAVSNVNKI IAPALINKNI PVTNQAAIDKYMIDLDGTENKEKLGANAILGVSLAVCK GVITAVSNVNTTIAPAIIQKNIPVTDQAAIDRFMIDLDGTENKEKLGANAILGVSLAVCK

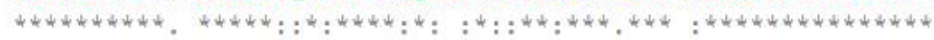

AGAAELNLPLYRYIAKLAGHRDVIMPVPAFNVINGGSHAGNKLAMQEFMILPTGASSETE AGAAEAGLPLYRYIARLAGHEDVIMPVPAFNVINGGSHAGNKLAMQEFMILPTGASSFTE AGAAEAGLPLYRYIARLAGHENVIMPVPAFNVINGGSHAGNLAMQEFMILPTGASSFTE

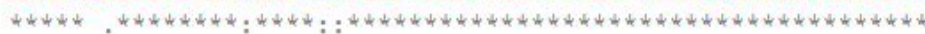

AMQMGSEVYHNLKAVIRREFGLDACNVGDEGGFAPNIQDNMKGLQLIEEAIRIAGYTGKV AMQIGTEVYHNLKAVIKREYGLDACNVGDEGGFAPNIQDNMKGLQLIEEAIKIAGYTGKV AMKIGSEVYHNLKAVIKREYGLDACNVGDEGGFAPNIQDNMKGIQLIEEAIKIAGYTGKV

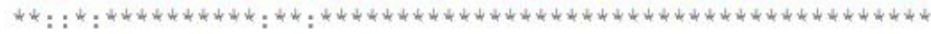

Figure 3 Multiple sequence alignment of phosphopyruvate hydratase of $S$. mansoni (G4VQ58); enolase of S. haematobium (XP_01293992.1) and SJCHGC00471 protein of $S$. japonicum (AAW24521.1)

\section{Legend}

"*” denotes that the amino acid in that column are identical in all sequence in the alignment. ":" denotes conserved regions i.e. amino acid with strongly similar properties. "." denotes semiconserved regions. The red color shows hydrophobic residues, blue color shows acidic residues, magenta shows basic residues, green shows hydroxyl residues while grey color show unusual amino acids. The colors in the alignments show the locations of similarity and difference among the sequence based on the chemical nature of the amino acid residues 

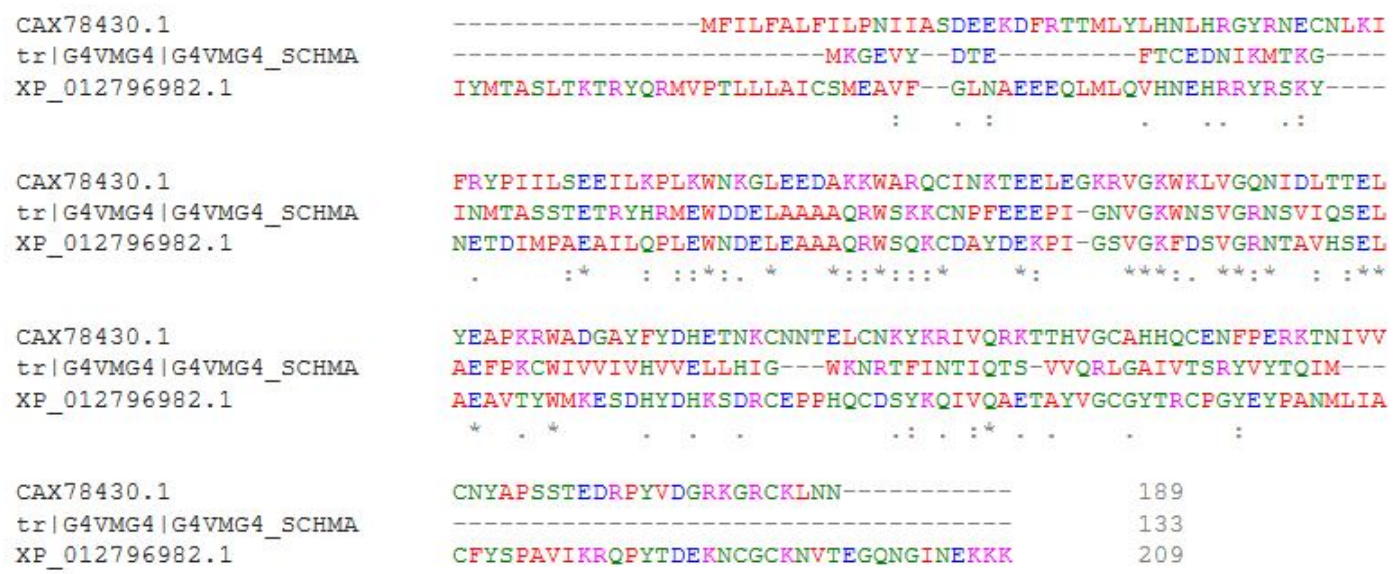

Figure 4 Multiple sequence alignment of venom allergen-like (VAL) 3 protein (G4VMG4) of S. mansoni; peptidase inhibitor 16, partial of S. haematobium (XP_012796982.1) and peptidase inhibitor 16,partial of S. japonicum (CAX78430.1)

\section{Legend}

“*” means that the amino acid in that column are identical in all sequence in the alignment. ":" denotes conserved region i.e. amino acid with strongly similar properties. “.” denotes semiconserved region. The red color shows hydrophobic residues, blue color shows acidic residues, magenta shows basic residues, green shows hydroxyl residues while grey color show unusual amino acids. The colors in the alignments show the locations of similarity and difference among the sequence based on the chemical nature of the amino acid residues 
Table 3. Drugs and compounds active against potential multi-species markers of medically important schistosomes

\begin{tabular}{|c|c|c|c|c|}
\hline $\begin{array}{l}\text { Markers in } \\
\text { all } 3 \text { species } \\
\text { (Query) }\end{array}$ & Potential Drugs and compounds & Drug Bank ID & Status & $\begin{array}{l}\text { Similarity to Human } \\
\text { form (coverage; } \\
\text { identity \%) }\end{array}$ \\
\hline $\begin{array}{l}\text { Putative } \\
\text { inorganic } \\
\text { pyrophospha } \\
\text { tase }\end{array}$ & DB06851; DB07291 & $\begin{array}{l}\mathrm{N} \text {-(pyridin-3-ylmethyl) aniline;5-amino-1-(4- } \\
\text { chlorophenyl)-1H-pyrazole-4-carbonitrile }\end{array}$ & $\mathrm{E}$ & $89 ; 51$ \\
\hline $\begin{array}{l}\text { Putative } \\
\text { ADP, ATP } \\
\text { carrier } \\
\text { protein }\end{array}$ & $\begin{array}{l}\text { DB00171;DB00720;DB02426;DB03429; } \\
\text { DB04178;DB01736;DB01077 }\end{array}$ & $\begin{array}{l}\text { ATP; Clodronic acid; Carboxyatractyloside; } \\
\text { Tetrastearoyl cardiolipin; Di-Stearoyl-3-Sn- } \\
\text { Phosphatidylcholine;[3- } \\
\text { (Dodecanoylamino)Propyl](Hydroxy)Dimethylammoni } \\
\text { um;Etidronic acid }\end{array}$ & $\begin{array}{l}\text { I, nutraceutical;A, I, } \\
\text { vet } A ; E ; E ; E ; E ; A\end{array}$ & $91 ; 42$ \\
\hline $\begin{array}{l}\text { Venom } \\
\text { allergen-like } \\
\text { (VAL) } 3\end{array}$ & not found & & & \\
\hline $\begin{array}{l}\text { Putative } \\
\text { ATP } \\
\text { synthase } \\
\text { alpha } \\
\text { subunit } \\
\text { vacuolar } \\
\end{array}$ & DB00630;DB01077;DB06733;DB06734 & $\begin{array}{l}\text { Alendronic acid; Etidronic acid; Bafilomycin } \\
\text { A1;Bafilomycin B1 }\end{array}$ & $\mathrm{A} ; \mathrm{A} ; \mathrm{E} ; \mathrm{E}$ & $98 ; 77.97$ \\
\hline $\begin{array}{l}\text { Calreticulin } \\
\text { autoantigen } \\
\text { homolog }\end{array}$ & $\begin{array}{l}\text { DB00025; } \\
\text { DB00031;DB06245;DB01065;DB11093; } \\
\text { DB11348;DB09130;DB13998;DB13999; } \\
\text { DB13949;DB14481;DB14520 }\end{array}$ & $\begin{array}{l}\text { Antihemophilic factor, human recombinant; } \\
\text { Tenecteplase; Lanoteplase; Melatonin; Calcium citrate; } \\
\text { Calcium Phosphate; Copper; Lonoctocog alfa; } \\
\text { Moroctocog alfa;Ferric cation; Calcium phosphate } \\
\text { dihydrate; Tetraferric tricitrate decahydrate }\end{array}$ & $\begin{array}{l}\text { A, I; A; I;A, } \\
\text { nutraceutical, vet_A;A, } \\
\text { I;A;A, I;A, I;A;A;A;A }\end{array}$ & $84 ; 56$ \\
\hline $\begin{array}{l}\text { Putative } \\
\text { rab9 }\end{array}$ & DB04315 & Guanosine-5'-Diphosphate & & $100 ; 63.7$ \\
\hline $\begin{array}{l}\text { Putative heat } \\
\text { shock } 70\end{array}$ & $\begin{array}{l}\text { DB04216; DB07045; DB09130; } \\
\text { DB01254; DB11638 }\end{array}$ & $\begin{array}{l}\text { Quercetin;(2R,3R,4S,5R)-2-[6-amino-8-[(3,4- } \\
\text { dichlorophenyl) methylamino]purin-9-yl]-5- } \\
\text { (hydroxymethyl)oxolane-3,4-diol;Copper;Dasatinib; } \\
\text { Artenimol }\end{array}$ & E, I; A;I & $93 ; 74.84$ \\
\hline $\begin{array}{l}\text { Elongation } \\
\text { factor 1- } \\
\text { alpha }\end{array}$ & DB11638 & Artenimol & E, I & $100 ; 78.3$ \\
\hline $\begin{array}{l}\text { Phosphopyr } \\
\text { uvate } \\
\text { hydratase }\end{array}$ & $\begin{array}{l}\text { DB09130; DB01593; DB11638; } \\
\text { DB14487; DB14533; DB14548; DB02726 }\end{array}$ & $\begin{array}{l}\text { Copper; Zinc; Artenimol; Zinc acetate; Zinc } \\
\text { chloride;Zinc sulfate, unspecified form;2- } \\
\text { Phosphoglycolic Acid }\end{array}$ & $\begin{array}{l}\text { A, I; A, I; E, I;A, I;A, } \\
\text { I;A, E;E }\end{array}$ & $99 ; 75$ \\
\hline $\begin{array}{l}\text { Eukaryotic } \\
\text { translation } \\
\text { initiation }\end{array}$ & not found & & & $100 ; 54.1$ \\
\hline
\end{tabular}


Methylene]Triphosphate;3-phospho-D-glyceric acid; erate kinase DB09130; DB11638

A: approved; Experimental, I: investigational 


\section{DISCUSSION}

Schistosomiasis, a devastating and highly prevalent neglected tropical disease (NTD), is endemic in Nigeria (reviewed in Abdulkadir et al., 2017; Eke et al 2020). The emergence of schistosome parasites that are resistant to the traditional treatment due to over-reliance on praziquantel demands the development of newer and more effective treatment which requires accurate diagnostic methods (Fernandes et al., 2018). More needs to be known about the molecular pathology that influences the outcome of the infection by $S$. haematobium in order to develop new diagnostics, therapeutic and infection prevention strategies (Weerakoon et al., 2018).

The composition of the urine microbiome in schistosomiasis and its associated functions are being tackled by genomic sequencing technology. The identification of proteins common to all species of schistosomes will provide targets for developing drugs or vaccine to control schistosomiasis and the associated bladder cancer in view of the growing concern about resistance developing to the existing therapeutic (Magalhaes et al., 2016). The detection of cancer-associated biomarkers, preferably isolated from urine and blood, has therefore become important. Such biomarkers are now being developed and will provide tools that could be useful to evaluate the specific effects of long-term exposure to $S$. haematobium; cancer-specific urine biomarkers may therefore, play an important role in diagnosis of people with long-term $S$. haematobium infections (Sotillo et al., 2016).

This study was performed to establish homology of the 36 biomarker proteins evaluated in a previous study (Onile et al., 2017) in other schistosome species. It was found that protein homologues of the $36 \mathrm{~S}$. mansoni biomarker proteins are present in S. haematobium and S. japonicum. Identification of homologues of these biomarker proteins could be used for early diagnosis of schistosomiasis and schistosomiasis associated bladder cancer and could also provide targets for developing drugs or vaccines that can be effective against all species of schistosomes.

The multiple sequence alignment was done by aligning $S$. mansoni biomarker proteins with their respective identical proteins retrieved. The basic information provided by the multiple sequence alignment is the identification of conserved sequence regions which is useful in designing wet laboratory experiment to test and modify the functions of these proteins, in predicting the function and structure of these proteins. 
bioRxiv preprint doi: https://doi.org/10.1101/2020.09.07.285767; this version posted September 7, 2020. The copyright holder for this preprint (which was not certified by peer review) is the author/funder, who has granted bioRxiv a license to display the preprint in perpetuity. It is made available under aCC-BY 4.0 International license.

Calreticulin-like protein of $S$. mansoni which is a $\mathrm{Ca} 2+$ binding/storage protein, being found in a number of different animal taxa, and has been considered as a novel antigen for the detection of anti-S. mansoni antibodies (Wang et al., 2018). It has homologues in both $S$. haematobium and $S$. japonicum with many identical amino acids and conserved regions when aligned (Figure 1).

Putative actin -1 has been identified as a possible drug target for the treatment of schistosomiasis as a strong association between actin and $S$. mansoni adult worm surface membranes has been confirmed (Fernandes et al., 2011). Studies have described the role of actin in enhancing the activity of praziquantel (PQZ) treatment of schistosomiasis. It is suggested that PQZ intercalates in the surface membrane lipid bi-layers, thereby inducing tegumental changes that leads to antigen exposure, including actin. This study showed that putative actin-1 protein has a homolog in other Schistosoma species, with many identical regions and conserved regions (Figure 2).

Phosphopyruvate hydratase is homologous to enolase protein in S. haematobium (Figure 3), and is implicated in autoimmune diseases; its utilization by pathogens while invading host tissue is well documented. Therefore, it is a key player in understanding the host-parasite interaction, and it offers a target for chemo- and immunotherapy (Liu et al., 2014). Phosphopyruvate hydratase, elongation factor 1-alpha and putative actin-1 protein have been identified as eggshell protein markers that can induce cellular or antibody responses and may be useful schistosomiasis diagnostic candidates. They have also been identified as putative $S$. mansoni biomarker proteins (Onile et al., 2017). They all have homologues in both $S$. haematobium and S. japonicum with many conserved regions and semi conserved regions in the multiple sequence alignment (Figure 4.10).

HSP 60 is a molecular chaperon (Ludolf et al., 2014) which has a homologue in S. haematobium, though no significant similarity was found between the protein sequence and S. haematobium whole genome shotgun sequence; but no protein similar to HSP 60 was found in S. japonicum though it has significant similarity with $S$. japonicum whole genome shotgun sequence. The alignment of HSP 60 with its homologue in S. haematobium showed many conserved regions and regions where all the amino acids in the sequences were identical.

Venom allergen-like (VAL) proteins are associated with excretion/secretion products and extracellular environment of the parasite; they have been used as a trial vaccine against hookworm infections in humans (Wilbers et al, 2018). The VAL protein families are abundant in different helminth species including gastrointestinal nematodes, where they are known to carry 
out several roles in the infective activities of parasites (Tribolet et al., 2015). Venom allergen-like (VAL) 3 was identified among the proteins secreted in the tunnels formed by destruction of epidermal cells by cercariae, during the first two hours of penetration of human skin. Later, the protein was found to have the ability to bind lipids in vitro and complement the sterol export phenotype of yeasts in vivo (Fernandes et al., 2018). In this study, we showed that venom allergen-like protein has homologues in both $S$. haematobium and $S$. japonicum but with few conserved and semi-conserved regions (Figure 3).

Elongation factor 1-alpha, phosphopyruvate hydratase and histone-4 were all identified as potential Schistosoma biomarkers (Onile et al., 2017). These proteins have been identified previously in purified eggshell fragments of Schistosoma mansoni and also figured as schistosome antigens which may induce cellular or antibody responses (Dvorak et al., 2016). These eggshell markers may be very useful schistosomiasis diagnostic candidates rather than vaccine candidates, since such a vaccine would be likely to target the eggs and further encourage granuloma formation and pathology rather than priming the immune system against the parasite. These proteins all have homologues in other Schistosoma species with enormous conserved regions

Elongation factor 1-alpha has homologues in both S. haematobium and S. japonicum with many regions where the amino acids in the sequences are identical and many conserved regions occurring in the alignment of the proteins.

Lastly, of interest were the potential targets compounds for the homologues consistent in all three species. Although information from the drugbank database is often the result of testing/current testing on humans, some of the predictions could be of future use. For instance, Artenimol, which occurs often in Table 3, is being investigated for malaria treatment, as it is partly related to the Artemisinins which have been previously in small scale trials for parasitic disease treatment (https://clinicaltrials.gov/ct2/show/NCT02653898). A modified phosphatidylcholine was also a potential target for an ATP carrier protein (Table 3). This may make biological sense as we previously reported that changes in phosphatidylcholine metabolism was a hallmark of schistosomiasis (Adebayo et al, 2018). The nutraceutical elements are also interesting as they are cheaply available if they do have any benefits.

\section{CONCLUSION}

Homology of the identified $S$. mansoni biomarker proteins was established in both $S$. haematobium and S. japonicum. This will help in early diagnosis of schistosomiasis and associated bladder cancer, although wet laboratory experiments are strongly indicated to serve as 
confirmation to the results of this study. This study can also help to provide targets for drugs or vaccines that can be simultaneously effective against all species of schistosomes.

\section{MATERIALS AND METHODS}

\section{Data collection}

Protein sequences of the 36 schistosome biomarkers were retrieved from the Uniprot database https://www.uniprot.org/ in FASTA format. Schistosoma haematobium and S. japonicum whole genome shotgun sequences were retrieved from GenBank https://www.ncbi.nlm.nih.gov/genbank/ as nucleotide and they were translated into protein format using EXPASY translating tool https://web.expasy.org/translate /.

\section{SMARTBLAST}

The $36 S$. mansoni biomarker proteins sequence in FASTA format were SMARTBLASTed https://blast.ncbi.nlm.nih.gov/smartblast/smartBlast.cgi to find protein sequences of other organism that are similar to the query protein sequence. The FASTA formats of protein sequences identical to each of the thirty-six protein were retrieved and used for multiple sequence alignment.

\section{Homology determination methods}

The retrieved biomarker protein sequences were BLASTed against Schistosoma haematobium and Schistosoma japonicum translated whole genome shotgun sequence to search for homologous sequences. Sequence thus obtain were then aligned using BLASTP https://blast.ncbi.nlm.nih.gov to show the region of similarity.

\section{Multiple Sequence Alignment}

Multiple alignments of protein sequences are important in studying sequences and providing basic information about conserved sequence region. Each of the thirty-six S.mansoni biomarker protein sequences were aligned with similar S. haematobium and S. japonicum protein sequences found when each of the protein was Smart Blasted. Multiple sequence alignment for each protein was done using Clustal Omega https://www.ebi.ac.uk/Tools/msa/clustalo/ which is a multiple 
sequence alignment program. The input protein sequences which were aligned were all in FASTA format.

\section{Potential Therapeutic targets}

Markers with homologues in all three species were used as query on the drugbank database(drugbank.ca) in order to identify potential therapeutic targets which were already in use in humans or being investigated.

\section{REFERENCES}

Abdulkadir, A., Ahmed, M., Abubakar, B.M., Suleiman, I.E., Yusuf, I., Imam, I.M., Sule, A.A, Tela, U.M., Dogoe, H.M., Yakasai, A.M, and Musag, B.M. (2017). Prevalence of urinary schistosomiasis in Nigeria, 1994-2015: Systematic review and meta-analysis. African Journal of Urology

Adebayo AS, Mundhe SD, Awobode HO, Onile OS, Agunloye AM, Isokpehi RD, Shouche YS, Santhakumari B, Anumudu CI. 2018 Metabolite profiling for biomarkers in Schistosoma haematobium infection and associated bladder pathologies. PLoS Negl Trop Dis.

12(4):e0006452. doi: 10.1371/journal.pntd.0006452.

Cai, P., Liu, S., Piao, X. and Hou, N. (2017). A next-generation microarray further reveals stageenriched gene expression pattern in the blood fluke Schistosoma japonicum. Parasites \& Vectors (2017) 10:19 DOI 10.1186/s13071-016-1947-x

Carlomagno N, Incollingo P, Tammaro V, Peluso G, Rupealta N, Chiacchio G, Sotelo M.L.S, Minieri G, Pisani A, Riccio E, Sabbatini M, Bracale U.M, Calogero A, Dodaro C.A. and Santangelo M. (2017). Diagnostic, Predictive, Prognostic, and Therapeutic Molecular Biomarkers in Third Millennium: A Breakthrough in Gastric Cancer. Hindawi BioMed Research International Volume 2017, Article ID 7869802, 11 pages https://doi.org/10.1155/2017/7869802

Colley, D.G., Bustinduy, A.L., Secor, W.E., King, C.H., (2014). Human schistosomiasis. Lancet 383, 2253-2264. 
Dawaki, S., Al-Mekhlafi, H.M., Ithoi, I., Ibrahim, J., Abdulsalam, A.M., Ahmed, A., Sady, H., Atroosh, W.M., Al-Areeqi, M.A., Elyana, F.N., Nasr N.A. and Surin J. (2016) Prevalence and risk factors of schistosomiasis among Hausa communities in Kano State, Nigeria. Rev Inst Med Trop Sao Paulo.58:54.

Dudek, A.M., Grotenhuis, A.J., Vermeulen, S.H., Kiemeney, L.A. and Verhaegh, G.W. (2013) Urinary Bladder Cancer Susceptibility Markers. What Do We Know about Functional Mechanisms?. Int. J. Mol. Sci. 2013, 14, 12346-12366; doi:10.3390/ijms140612346

Dvořák, J., Fajtová, P., Ulrychov, L. and Leontovy A. (2016). Excretion/secretion products from Schistosoma mansoni adults, eggs and schistosomula have unique peptidase specificity profiles. Biochimie. 2016 March ; 122: 99-109. doi:10.1016/j.biochi.2015.09.025.

Fernandes, R.S., Luis, B., Andre, G.V., Patrícia, S.G., Miyasatod, A., Leonardo, E.N., Ana, P.F. and Luciana, L.T.O. (2018). Schistosoma mansoni venom allergen-like protein 18 (SmVAL18) is a plasminogen-binding protein secreted during the early stages of mammalian-host infection. Molecular \& Biochemical Parasitology. 221: 23-31. https://doi.org/10.1016/j.molbiopara.2018.02.003

French, M.D., Evans, D., Fleming, F.M., Secor, W.E., Biritwum, N.K. and Brooker S.J. (2018). Schistosomiasis in Africa: Improving strategies for long-term and sustainable morbidity control. PLoS Negl Trop Dis 12(6): e0006484. $\underline{\text { https://doi.org/ }}$ 10.1371/journal.pntd.0006484

Gulìa, C S., Baldassarra, F., Signore, G., Rigon, V., Pizzuti, M., Gaffi, V., Briganti, A., Porrello, R. and Piergentili, R. (2017). Role of Non-Coding RNAs in the Etiology of Bladder Cancer. Genes 2017, 8, 339; doi:10.3390/genes8110339

Honeycutt, J., Hammam, O., Fu, C.L. and Hsieh, M.H. (2014). Controversies and challenges in research on urogenital schistosomiasis-associated bladder cancer. Trends Parasitol. 2014 July ; 30(7): 324-332. doi:10.1016/j.pt.2014.05.004.

Huang, Z., Ma, L. and Huang, C. (2017). Proteomic profiling of human plasma for cancer biomarker discovery, Proteomics 17, 6, 2017, 1600240 DOI 10.1002/pmic.201600240

Hwang, H., Hwang, B.W., and Bueno, J., (2018). Biomarkers in Infectious Diseases. Hindawi 
Disease Markers Volume 2018, Article ID 8509127, 2 pages https://doi.org/10.1155/2018/8509127

Kardoush, M.I, Ward, B.J. and Ndao, M. (2016). Identification of Candidate Serum Biomarkers for Schistosoma mansoni Infected Mice Using MultipleProteomic Platforms. PLoS ONE $11(5)$.

Liu, S., Cai, P., Piao, X., Hou, N., Zhou, X., Wu, C., Wang, H. and Chen, Q. (2014) Expression profile of the Schistosoma japonicum degradome reveals differential protease expression patterns and potential anti-schistosomal intervention targets. PLoS Comput Biol. 2014; 10:e1003856. [PubMed: 25275570]

Ludolf, F., Patroci'nio P.R., Corre^a-Oliveira, R., Gazzinelli A. and Falcone F.H. (2014). Serological Screening of the Schistosoma mansoni Adult Worm Proteome. PLoS Negl Trop Dis 8(3): e2745. doi:10.1371/journal.pntd.0002745

Magalhãesa, L.G., Limaa, T.C., de Paulab, R.G., Morais, E.R., Aguiara, D.P., Gardinassib, L.G., Garciab, G.R., Laurentizd, R.S., Rodrigues, V., Bastose, J.K., Filhof, A.A.S., Yatsudae, A.P., Cunhaa W.R. and Silva M.L.A. (2016). Effects of (-)-6,6_-dinitrohinokinin on adult worms of Schistosoma mansoni: a proteomic analyses. Revista Brasileira de Farmacognosia 26 (2016) 334-341. http://dx.doi.org/10.1016/j.bjp.2016.02.001

Masamba, P., Adenowo, A.F., Oyinloye, B.E. and Kappo, A.P. (2016). Universal Stress Proteins as New Targets for Environmental and Therapeutic Interventions of Schistosomiasis, Int. J. Environ. Res. Public Health 2016, 13, 972; doi:10.3390/ijerph1310097

Molehin, AJ (2020) Schistosomiasis vaccine development: update on human clinical trials. J Biomed Sci 27, 28 https://doi.org/10.1186/s12929-020-0621-y

Onile, O.S., Anumudu, C.I., Calder, B., Nelson, C.S. and Jonathan, M.B. (2017). Quantitative label-free proteomic analysis of human urine to identify novel candidate protein biomarkers for schistosomiasis. PLoS Negl Trop Dis 11(11): e0006045. https://doi.org/10.1371/journal.pntd.0006045 
Schmitz-Dräger, B.J., Droller, M., Lokeshwar, V.B., M’Liss, Y.L. and Hudson A. (2015). Molecular Markers for Bladder Cancer Screening, Early Diagnosis, and Surveillance: The WHO/ICUD Consensus. Urol Int 2015;94:1-24 DOI: 10.1159/000369357

Secor W.E. and Montgomery S.P. (2015). Something old, something new: is praziquantel enough for schistosomiasis control? Future Med. Chem. (2015) 7(6), 681-684

Sotillo, J., Doolan, D. and Loukas, A. (2016). Recent advances in proteomic applications for schistosomiasis research: potential clinical impact, Expert Review of Proteomics. DOI: $10.1080 / 14789450.2017 .1271327$

Tribolet, L., Cantacessi, C., Pickering, D.A., Navarro, S., Doolan, D.L. and Trieu, A. (2015). Probing of a human proteome microarray with a recombinant pathogen protein reveals a novel mechanism by which hookworms suppress B-cell receptor signaling. J. Infect. Dis. 2015; 211:416 \pm 425 . https://doi.org/10.1093/infdis/ jiu451 PMID: 25139017

Tsim, S., Kelly, C. and Alexander, L. (2016). Diagnostic and Prognostic Biomarkers in the Rational Assessment of Mesothelioma (DIAPHRAGM) study: protocol of a prospective, multicentre, observational study. BMJ Open 2016;6:e013324. doi:10.1136/bmjopen-2016013324

Wang, T., Zhao, M., Rotgans, B.A., Strong, A., Liang, D. and Ni, G. (2018). Proteomic Analysis of the Schistosoma mansoni Miracidium. PLoS ONE 11(1):e0147247. doi: 10.1371/journal.pone.0147247

Weerakoon, K.G., Gordon, C.A. and McManus, D.P. (2018). DNA diagnostics for schistosomiasis control. Trop. Med. Infect. Dis. 2018, 3, 81; doi:10.3390/tropicalmed3030081.

Weifeng, G., Joseph, W.M., Zhisheng, D., Yumin, Z. and Wei, H. (2018). Advances in diagnosis of schistosomiasis. Microbiol Curr Res. 2018;2(2):3-8.

White Bear, J., Long, T., Skinner D. and McKerrow J.H. (2018) Predictions of novel Schistosoma mansoni - human protein interactions consist. Scientific Reports (2018) 8:13092 DOI:10.1038/s41598-018-31272-1

Wilbers RHP, Schneiter R, Holterman MHM, Drurey C, Smant G, Asojo OA, et al. (2018) Secreted venom allergen-like proteins of helminths: Conserved modulators of host responses in animals and plants. PLoS Pathog 14(10): e1007300. https://doi.org/10.1371/journal.ppat. 1007300

World Health Organization (WHO, 2015). Preventive chemotherapy in human helminthiasis: coordinated use of antihelminthic drugs in control interventions: a manual for health 
professionals and programme managers $\underline{\text { www.who.int/schistosomiasis/en/. }}$ 14 $^{\text {th }}$ September,2018

Yumin, Z, Weifeng, G. and Joseph, W.M. (2018) . Advances in diagnosis of schistosomiasis. Microbiol Curr Res. 2018;2(2):3-8.

Zheng, Y.L., Amr, S., Saleh, D.A., Dash, C. and Ezzat, S. (2012) Urinary bladder cancer risk factors in Egypt: a multicenter case-control study. Cancer Epidemiol Biomarkers. 


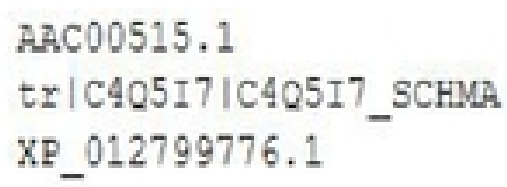

MILVLICELISYRVSGEKVWFSETFPDEKSIDGWIOSTFNGDROGEFKIEAGRSPVNPIE MLSILLTLLLSKYALGHEVWFSETFPNE-SIENWVOSTYMAEKOGEFKVEAGKSPVDPIE MFSALLVLLSEYALGHEVWFSETFPNE-SIEDWVQSTYNADRQGERKVEAGRSPVDPIE

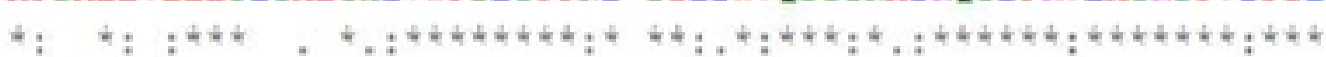

DLGLKTIQDARFYGIARKISEPFSNRDKTLVLOPTVRFDKTVTCGGAYIRLLGSDIDPKT DLGLKTTDARFYGIARKISEPFSNRGRTIVLQFTVRPDRTVSCGGAYIRLLGSDIDPRK DLGLKTIQDARFYGIARRISQPFSNRDKTMVLQFTVRPDRTVSCGGAYIRLIGSDIDPRK

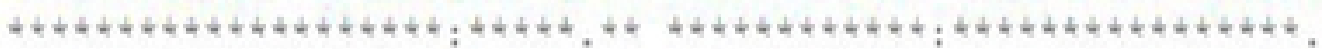

Figure 1 Calreticulin autoantigen homolog of $S$. mansoni (C4Q5I7); calreticulin of $S$. haematobium (XP_012799776.1) and calreticulin of S. japonicum (AAC00515.1) in multiple sequence alignment

\section{Legend}

"*" means that the amino acid in that column are identical in all sequence in the alignment. ":" denotes conserved regions i.e. amino acid with strongly similar properties. "." denotes semiconserved regions. The red color shows hydrophobic residues, blue color shows acidic residues, magenta shows basic residues, green shows hydroxyl residues while grey color show unusual amino acids. The colors in the alignments show the locations of similarity and difference among the sequence based on the chemical nature of the amino acid residues 


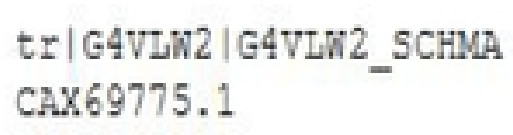

MAEEDVAALVIDNGSGUCKAGFAGDDAPRAVFPSIVGRPRHOGWVGMGOKDSYVGDEAO MAEEEVAALVIDNGSGMCKAGFAGDDAPRAVFPSIVGRPRHOGVMVGMGODSYVGDEAQ

Figure 2 Multiple sequence alignment of putative actin-1 of $S$. mansoni (G4VLW2) and actin $5 \mathrm{C}$ of $S$. japonicum (CAX75500.1)

\section{Legend}

"*" means that the amino acid in that column are identical in all sequence in the alignment. ":" denotes conserved regions i.e. amino acid with strongly similar properties. "." denotes semiconserved regions. The red color shows hydrophobic residues, blue color shows acidic residues, magenta shows basic residues, green shows hydroxyl residues while grey color show unusual amino acids. The colors in the alignments show the locations of similarity and difference among the sequence based on the chemical nature of the amino acid residues 
Aมพ24521.1

tr|G4VQ58|G4VO58_SCHMA

XP_012793992.1

AAW24521.1

tr|GAVQ58|G4VQ58_SCHMA.

$X_{-} P_{-} 012793992.1$
MAIAIHAROIFDSRGNETVEDLITARGLFRAAVPSGASTGVHEALELRDTNSAYMCK MSILTIHARQIFDSRGNPTVEVDLKTSKGLFRAAVPSGASTGVHEALELRDINSKAYMKK MSIISIHAROIFDSRGNPTVEVDLKTSRGLFRAAVPSGASTGVHEALELRDTKSTAYUGK

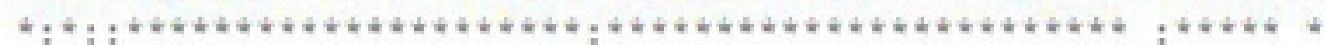

GVLTAVSNVNNI IAPALLKRQI PVTNQSEVDQRNIELDGKENKGNLGANAILGVSLAVCK GVLTAVSNVNKI IAPALINKNI PVTNQAAIDKYMIDLDGTENKEKLGANAILGVSLAVCR GVLTAVSNVNTTIAPALIQKNI PVTDQAAIDRENIDLDGTENKEKLGANAILGVSLAVCK

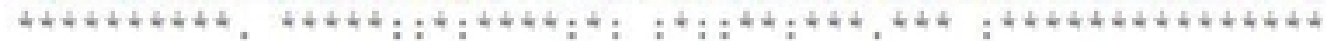

bioRxiv preprint doi: https://doi.org/10.1101/2020.09.07.285767; this version posted September 7, 2020. The copyright holder for this

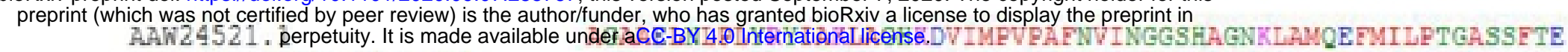
tr | G4VQ58 | G4VQ58_SCHMA XP_012793992.1

AAN24521.1 tr|G4VQ58 |G4VQ58_SCHMA XP_012793992.1
AGRAEAGLPLYRYIARLAGHEDVIMPVPAFNVINGGSHAGNKLANOEFMILPTGASSETE AGAREAGLPLYRYIAKLAGHENVIMPVPAFNVINGGSHAGNKLANQEFMILPTGASSFTE

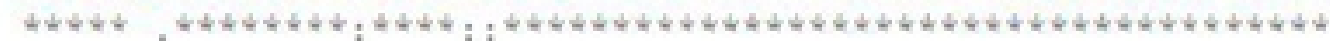

RMONGSEVYHNZRAVIRREFGLDACNVGDEGGFAPNI QDNMKGLQLIEEAIRIAGYTGKV RMQIGTEVYHNZKAVIKREYGLDACNVGDEGGRAPI QDNMKGLOLLEAIRIAGYTGKV RMRIGSEVYHNZKAVIKREYGLDACNVGDEGGFAPNI ODNMKGLOLLEAIRIAGYTGKV

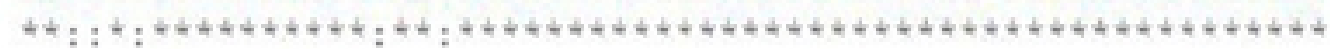

Figure 3 Multiple sequence alignment of phosphopyruvate hydratase of $S$. mansoni (G4VQ58); enolase of S. haematobium (XP_01293992.1) and SJCHGC00471 protein of S. japonicum (AAW24521.1)

\section{Legend}

"*" denotes that the amino acid in that column are identical in all sequence in the alignment.

":" denotes conserved regions i.e. amino acid with strongly similar properties. "." denotes semiconserved regions. The red color shows hydrophobic residues, blue color shows acidic residues, magenta shows basic residues, green shows hydroxyl residues while grey color show unusual amino acids. The colors in the alignments show the locations of similarity and difference among the sequence based on the chemical nature of the amino acid residues 

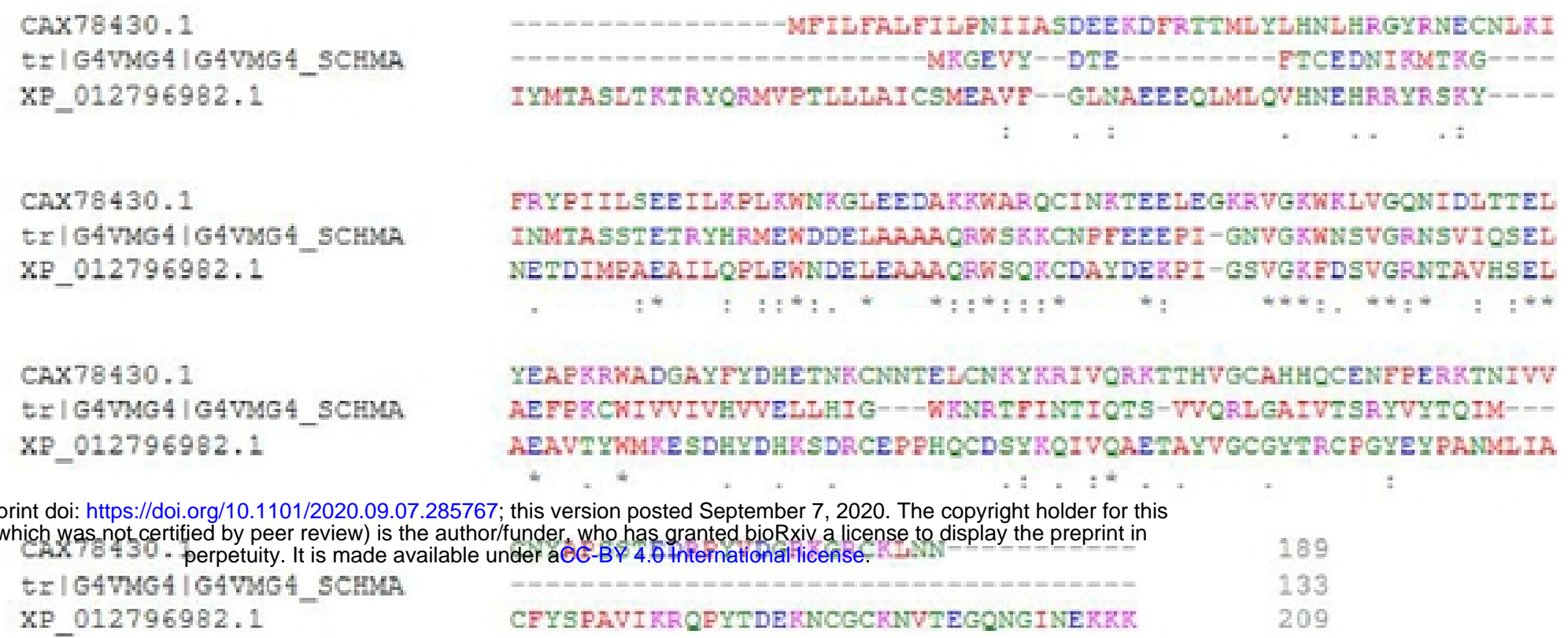

Figure 4 Multiple sequence alignment of venom allergen-like (VAL) 3 protein (G4VMG4) of S. mansoni; peptidase inhibitor 16, partial of $S$. haematobium (XP_012796982.1) and peptidase inhibitor 16, partial of $S$. japonicum (CAX78430.1)

\section{Legend}

"*" means that the amino acid in that column are identical in all sequence in the alignment. ":" denotes conserved region i.e. amino acid with strongly similar properties. "." denotes semiconserved region. The red color shows hydrophobic residues, blue color shows acidic residues, magenta shows basic residues, green shows hydroxyl residues while grey color show unusual amino acids. The colors in the alignments show the locations of similarity and difference among the sequence based on the chemical nature of the amino acid residues 
bioRxiv preprint doi: https://doi.org/10.1101/2020.09.07.285767; this version posted September 7, 2020. The copyright holder for this
preprint (which was not certified by peer review) is the preprint (which was not certified by peer review) is the author/funder, who has granted bioRxiv a license to display the preprint in
perpetuity. It is made available under aCC-BY 4.0 International license. 